HARRAN ÜNIVERSITESI MÜHENDISLIK DERGisi

HARRAN UNIVERSITY JOURNAL OF ENGINEERING

e-ISSN: 2528-8733

\section{HARRAN ÜNIVERSITTESI MÜHENDİSLİK DERGİİ}

HARRAN UNIVERSITY JOURNAL of ENGINEERING

e-ISSN: 2528-8733 (ONLINE)

URL: http://dergipark.gov.tr/humder

Ekonomizersiz Bir Tav Fırın Bacasının Sayısal Olarak İncelenmesi

Numerical Investigation of a Without Economizer Annealing Furnace Chimney

Yazar(lar) (Author(s)): Aykut GÜZEL ${ }^{1}$, Ismail HILLALI' ${ }^{2}$, M. Azmi AKTACİR ${ }^{3}$

${ }^{1}$ ORCID ID: 0000-0003-1321-4748

${ }^{2}$ ORCID ID: 0000-0001-7585-0016

${ }^{3}$ ORCID ID: 0000-0003-2345-7815

Bu makaleye şu şekilde atffta bulunabilirsiniz (To cite to this article): Güzel A., Hilali İ., Aktacir M.A., "Ekonomizersiz Bir Tav Fırın Bacasının Sayısal Olarak İncelenmesi”, Harran Üniversitesi Mühendislik Dergisi, 6(Özel Say1): 33-39, (2021).

Erişim linki (To link to this article): http://dergipark.gov.tr/humder/archive 
HRU Muh Der, 6(Özel Sayı): 33-39 (2021)

Mühendislik Dergisi

\title{
Ekonomizersiz Bir Tav Fırın Bacasının Sayısal Olarak İncelenmesi
}

\author{
Aykut GÜZEL ${ }^{1}$, İsmail HILALİ², M. Azmi AKTACIR ${ }^{3}$ \\ ${ }^{1}$ Adlyaman Üniversitesi, TBMYO, Makine ve Metal Bölümü, 02100, Merkez/Adiyaman \\ ${ }^{2}$ Harran Üniversitesi, Mühendislik Fakültesi, Makine Mühendisliği Bölümü, 63190, Haliliye/Şanlurfa \\ ${ }^{3}$ Harran Üniversitesi, Mühendislik Fakültesi, Makine Mühendisliği Bölümü, 63190, Haliliye/Şanlıurfa
}

\section{Makale Bilgisi \\ Başvuru: 12/01/2021 \\ Yayin: 01/11/2021}

\section{Anahtar Kelimeler}

Tav Firin Bacasl Hesaplamalı Akışkanlar Dinamiği

Saylsal Analiz

Autodesk CFD

\section{Keywords}

Annealing Furnaces

Chimney

Computational Fluid

Dynamics

Numerical Analysis

Autodesk CFD
$\ddot{O} \mathbf{z}$

Sanayi kuruluşları enerji tüketiminin en yoğun olduğu yerlerdir. Sanayide enerji verimliliği enerji kayıplarının belirlenmesi ve buna bağlı olarak enerji kayıplarını azaltmaya yönelik çalışmalar yapılarak gerçekleştirilir. Bu çalışmada; 1 sı geri kazanımı uygulamalarına katkıda bulunmak amaciyla egzoz gazı atık 1sı potansiyeli yüksek olan bir ekonomizersiz sıcak haddehane tav firınının baca gazı iç akışı sayısal olarak incelenmiştir. Sayısal hesaplamalar bir Hesaplamalı Akışkanlar Dinamiği (HAD) Analizi programı olan Autodesk CFD kullanılarak yapılmıştır. Baca modeli $85 \mathrm{~m}$ yükseklikte ve $3,62 \mathrm{~m}$ giriş çapındadır. Modelde $2.48 \mathrm{~m} / \mathrm{s} \mathrm{h}$ iz ve $650{ }^{\circ} \mathrm{C}$ sıcaklıkta egzoz gazı girişi sağlanmaktadır. Sayısal analizinin zamandan bağımsız olarak elde edildiği baca modelinin iç akışının her bölgesindeki sıcaklık ve hız dağılımları k-epsilon türbülans modeli ile incelenmiştir. Baca modelinin sıcaklık ve hız dağılımları dört farklı yükseklikteki yatay kesitten ve bir dikey kesitten elde edilmiştir. Sonuçlar incelendiğinde egzoz gazının tav fırın bacası içerisindeki sıcaklık profili, bacanın çıkışına doğru merkezinde sabit kalmakla birlikte bacanın merkezi ile duvarları arasındaki sıcaklık farkı azalma eğilimi göstermiştir. Tav fırın bacasının lokal hız profili incelendiğinde ise bacanın çıkışına doğru yaklaşık ilk $15 \mathrm{~m}$ 'de hızlı bir artış meydana geldiği ve sonrasında yaklaşık olarak sabit bir eğilimde olduğu gözlemlenmiştir. Yapılan bu çalışmalar doğrultusunda tav fırın bacalarının 1s1 geri kazanımı uygulamalarının geliştirilmesine katkıda bulunulmaya çalışılmıştır.

\section{Numerical Investigation of a Without Economizer Annealing Furnace Chimney}

\begin{abstract}
Industrial establishments are the places where energy consumption is most intense. In the industry, energy efficiency is achieved by determining energy losses and, accordingly, efforts to reduce energy losses. In this study; In order to contribute to heat recovery applications, the flue gas internal flow of without economizer hot rolling mill annealing furnace with a high exhaust gas waste heat potential was examined numerically. Numerical calculations were made using Autodesk CFD, a Computational Fluid Dynamics (CFD) Analysis program. The chimney model is $85 \mathrm{~m}$ in height and $3.62 \mathrm{~m}$ inlet diameter. Exhaust gas inlet of $2.48 \mathrm{~m} / \mathrm{s}$ speed and $650{ }^{\circ} \mathrm{C}$ temperature is provided in the model. Temperature and velocity distributions in each region of the internal flow of the chimney model, where numerical analysis is obtained independently of time, were examined with the k-epsilon turbulence model. The temperature and velocity distributions of the chimney model were obtained from four horizontal sections and one vertical section. When the results are examined, the temperature profile of the exhaust gas in the annealing furnace remains constant at the center towards the outlet of the chimney, but the temperature difference between the center of the chimney and its walls tended to decrease. When the local velocity profile of the annealing furnace chimney is examined, it is observed that there is a rapid increase in the first $15 \mathrm{~m}$ towards the exit of the chimney and then it has a nearly stable trend. In line with these studies, it has been tried to contribute to the development of heat recovery applications of annealing furnace chimneys.
\end{abstract}




\section{GIRISŞ (INTRODUCTION)}

Dünyada ve Türkiye'de enerjinin verimli bir şekilde kullanımını sağlamak günümüzde en gözde konulardan birisidir. Sera etkisi, küresel ssınma ve bunları takiben gerçekleşen iklim değişiklikleri, hava kirliliği ve tüm bunların canlılar üzerindeki birçok olumsuz etkilerin kaynağı enerji üretimi ve kullanımına dayanmaktadır [1]. Endüstriyel işletmelerde, enerjinin verimli kullanımını amaçlayan çalışmalar, enerji kaynaklarının verimli kullanımı ve çevreye olumsuz etkilerinin azaltılması yönünden bu problemlerin çözümü için önemli katkılarda bulunmaktadır [2,3]. Demir-Çelik, sanayi kuruluşları içerisinde enerjinin en yoğun kullanıldığı sektördür. Demir-Çelik sektörünün enerji tüketim miktarı dünyanın toplam enerji tüketim miktarının \%5'ini oluşturmaktadır [4].

Çeliklerin haddeleme işlemleri ile çeliği $1050-1300{ }^{\circ} \mathrm{C}$ sıcaklık aralığında isıtma işlemleri tav firınlarında yapılmaktadır [5]. Isıl verimleri \%35-45 arasında olan tav firınlarında 1sı kaybının en yoğun olduğu yer baca gazıdır. Tav firınlarında yüksek 1sitma yapılması sonucunda bacadan $650{ }^{\circ} \mathrm{C}$ sicaklıkta atık 1S1 enerjisi oluşmaktadır [6]. Atık 1sının geri kazanımı ile ilgili yapılabilecek çalışmalardan biri de ekonomizer uygulamalarıdır.

Akışkanlar mekaniği problemlerinin sayısal yöntemler ve algoritmalar kullanılarak analiz edilmeleri ve çözümlenmeleri için Hesaplamalı Akışkanlar Dinamiği (HAD) kullanılmaktadır. HAD analiz ve çözümlemelerinde kullanılan birçok yazılım programı bulunmaktadır. Autodesk CFD, Ansys Fluent, Solidworks Flow Simulation, Ansys CFX gibi yazılım programları HAD programı olarak kullanılmaktadır.

Bu çalışmada 1sı geri kazanımı uygulamalarına katkıda bulunmak amacıyla egzoz gazı atık 1sı potansiyeli yüksek olan ekonomizersiz bir sıcak haddehane tav fırınının baca gazı iç akışı ve sıcaklık alanları incelenmiştir. Sayısal hesaplamalar bir HAD Analizi programı olan Autodesk CFD kullanılarak yapılmıştır.

\section{SAYISAL MODELLEME}

Türkiye'de Tav firın bacası $85 \mathrm{~m}$ yükseklikte ve bacanın giriş çapı 3,62m'dir. Tav fırın bacasının iç akışını oluşturan egzoz gazı kok gazının yanma ürünleridir. Sayısal çözümde egzoz gazı bir gaz karışımı olarak tanımlanmıştır. Egzoz gazının yoğunluğu( $(\rho) 0,3421637 \mathrm{~kg} / \mathrm{m} 3$ ve viskozitesi $(\mu)$ ise $1,72 \mathrm{e}-05 \mathrm{~kg} / \mathrm{ms}$ alınmıştır. Sayısal analiz üç boyutlu ve zamandan bağımsız çözülmüş̧ür. Bacanın duvarları tuğla ve özgül 1sıs1 $1050 \mathrm{j} / \mathrm{Kg}-\mathrm{K}$ olarak tanımlanmıştır.

Model ağı, hesaplama hacmini küçük kontrol hacimlerine bölerek bu kontrol hacimlerinin her biri için matematiksel çözüm yaparak daha sonra bu çözümlerin birleştirilmesine dayanır. Şekil 1'de ağ yapıs1 gösterilen sayısal modelde; baca duvarının olduğu katı bölgede 241.450 hücreden oluşan tetrahedron ağ yapısı, baca içi akış hacminde ise 1.222 .720 elemandan oluşan tetrahedron ağ yapısı kullanılmıştır. Model boyunca akış ve ısı transferinin çözümlenmesi, zamandan bağımsız olarak kütlenin (süreklilik denklemi), momentumun ve enerjinin korunumu kanunlarından elde edilen kısmi türevli denklemlerin çözümlenmesi esasına dayanır [7].

Egzoz gazının bacaya girişinde "velocity", ve "temperature" sınır şartı, çıkışında "pressure"' sınır şartı katı (baca duvarları) yüzeylerde ise "'temperature" sınır şartı kullanılmıştır. Duvar sıcaklığ $115{ }^{\circ} \mathrm{C}$ olarak atanmıştır. Giriş sınırında yerçekimi etkileri dikkate alınmıştır. Giriş sınırında egzoz gazının bacaya giriş sicaklığ $650{ }^{\circ} \mathrm{C}$ ve hızı $2.48 \mathrm{~m} / \mathrm{s}$ olarak tanımlanmış ve çözümün zamandan bağımsız olması için "Steady State" seçilmiştir. Sayısal çözümde türbülans modeli olarak ekonomikliği ve pek çok akış olayında kabul edilebilir doğrulukta sonuç vermesi açısından diğer türbülans modellerine göre yaygın olarak kullanılan k-epsilon türbülans modeli kullanılmıştır. Ayrıca bu model duvar cidarlarındaki akış davranışlarını tahmin etmede ideal bir model olarak kullanılmaktadır. 


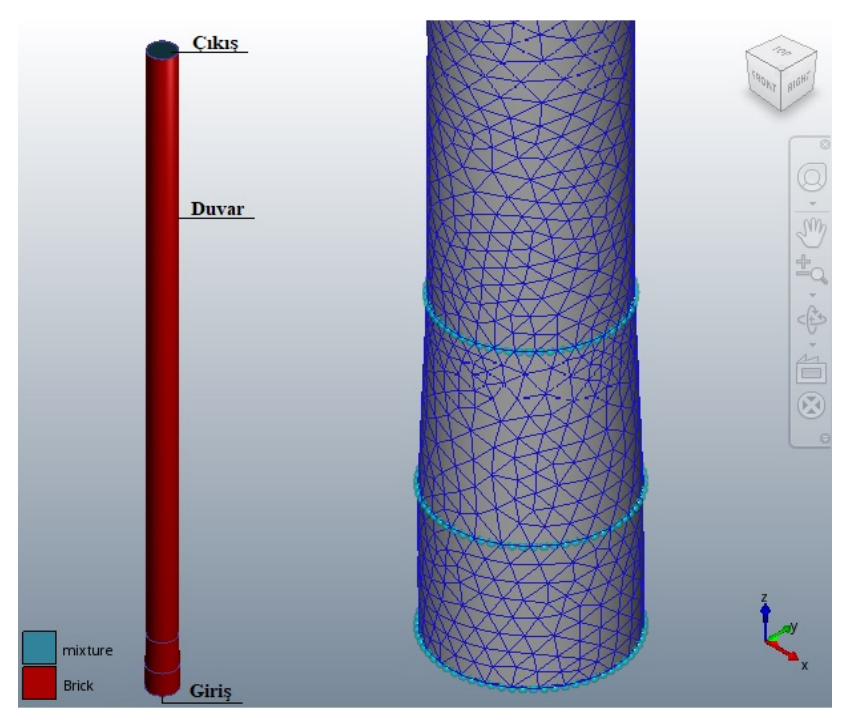

Şekil 1. Geometrik model ve ăg yapısı

\section{SAYISAL SONUÇLAR}

HAD analizinde ele alınan tav fırın bacasındaki meydana gelen türbülanslı akış, bacanın çeşitli kesitlerinden elde edilen sıcaklık dağılımları ve akım çizgileri cinsinden sunulmuştur. Çözüm sonuçları, Autodesk CFD programı ile alınmıştır. Çözüm alanında L1, L2, L3 ve L4 yatay kesitte düzlemler oluşturulmuştur. Düzlemler baca tabanından sırasıyla $5 \mathrm{~m}, 20 \mathrm{~m}, 50 \mathrm{~m}$ ve $80 \mathrm{~m}$ yüksekliktedir.
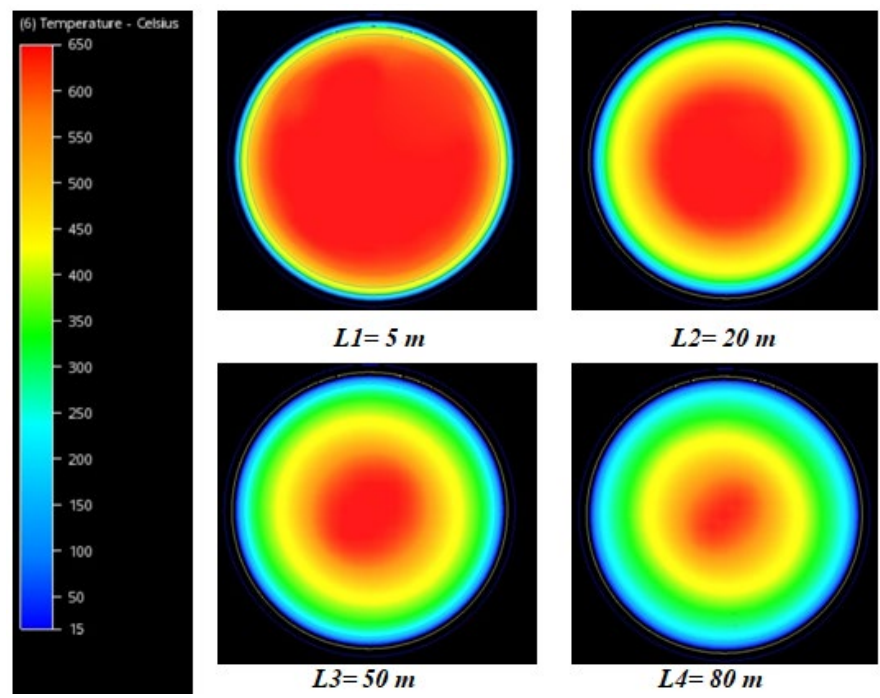

Şekil 2. L1, L2, L3 ve L4 düzlemlerinden elde edilen sıcaklık dăğllımları

Şekil 2'de L1, L2, L3 ve L4 düzlemlerinin k-epsilon türbülans model simülasyonlarından elde edilen sıcaklık dağglımları gösterilmiştir. Sıcaklık kontur değerleri Şekil 2'nin sol tarafında belirtilmiştir. Tüm düzlemlerde baca merkezindeki sıcaklık en yüksek seviyede olup, bu seviye merkezden duvarlara doğru yaklaştıkça azalma göstererek korunmakta, duvar yakınlarında ise aniden düşmektedir. Düzlemlerin ortalama sıcaklık değerleri L1 $619^{\circ} \mathrm{C}, \mathrm{L} 2565{ }^{\circ} \mathrm{C}$, L3 $508^{\circ} \mathrm{C}$ ve L4 $470{ }^{\circ} \mathrm{C}$ olduğu görülmüsstür. 

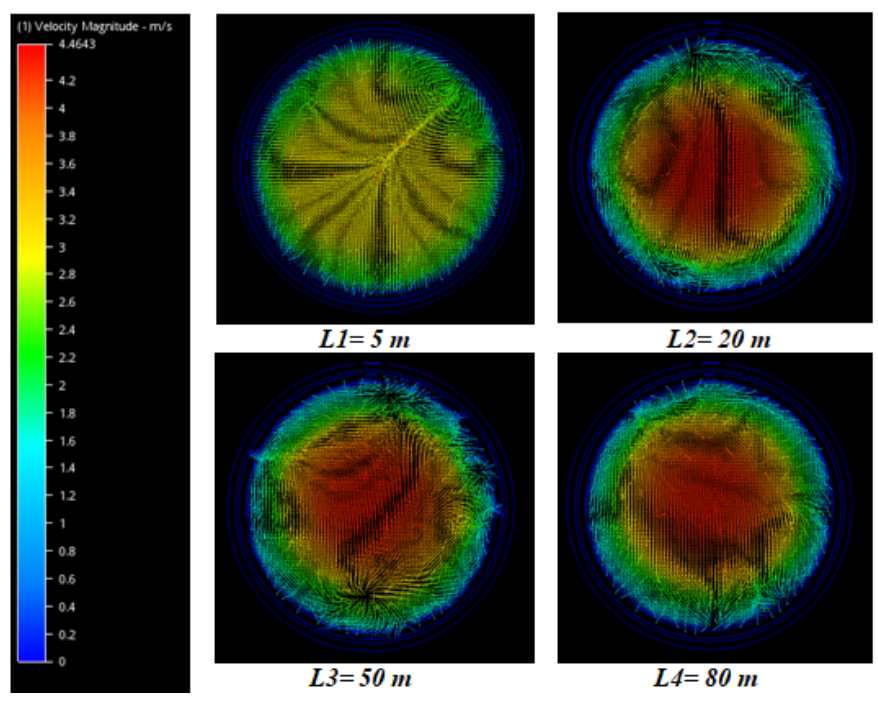

Şekil 3. L1, L2, L3 ve L4 düzlemlerinden elde edilen k-epsilon türbülans model simülasyonundan elde

edilen hız vektörü dağılımları

Şekil 3'de L1, L2, L3 ve L4 düzlemlerinin k-epsilon türbülans model simülasyonundan elde edilen hiz vektörü dağılımları verilmiştir. Bu düzlemlerden elde edilen ortalama hız değerleri L1 düzlemi için 2,85 $\mathrm{m} / \mathrm{s}$, L2 düzlemi için $3,32 \mathrm{~m} / \mathrm{s}$, L3 düzlemi için $3,30 \mathrm{~m} / \mathrm{s}$ ve $\mathrm{L} 4$ düzlemi için $3,27 \mathrm{~m} / \mathrm{s}$ dir. L1 düzleminde hız vektörleri baca duvarlarından merkeze doğru yönelmiş; L2 ve L3 düzlemlerinde ise baca duvarlarına yakın bölgelerde yer yer girdap oluşumu gözlemlenmiştir. Hız mertebeleri incelendiğinde L1 düzleminde hız diğer düzlemlere doğru bir artış göstermiş ve L2 düzleminden sonra baca çıkışına kadar yaklaşık olarak sabit kalmıştır.

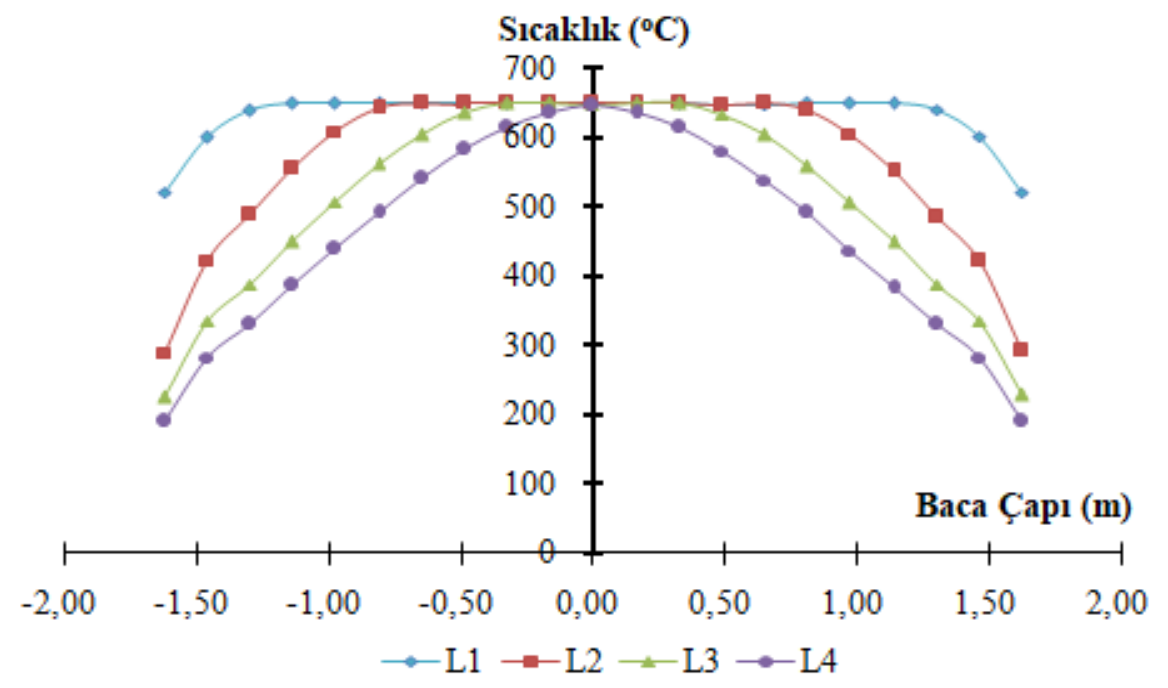

Şekil 4. L1, L2, L3 ve L4 düzlemlerinin merkezlerinden geçen x-simetri ekseni çizgisi boyunca slcaklık dă̆ılımı

Şekil 4'de L1, L2, L3 ve L4 düzlemlerinin merkezlerinden geçen x-simetri ekseni çizgisi boyunca kepsilon türbülans modeli çözümünden elde edilen sıcaklık dağılımı gösterilmektedir. 0 noktası bacanın merkez noktasına karşılık gelmektedir. Tüm düzlemlerde bacanın merkez çizgisi boyunca sıcaklık sabit kalmış ve baca merkezinin sağ ve sol tarafındaki sıcaklık dağılımlarının simetrik olduğu gözlemlenmiştir. Sıcaklık dağılımları baca duvarına yaklaştıkça azalma eğiliminde ve azalma eğiliminin baca girişinden çıkışına doğru yükseklik arttıkça arttı̆̆ı gözlemlenmektedir. 


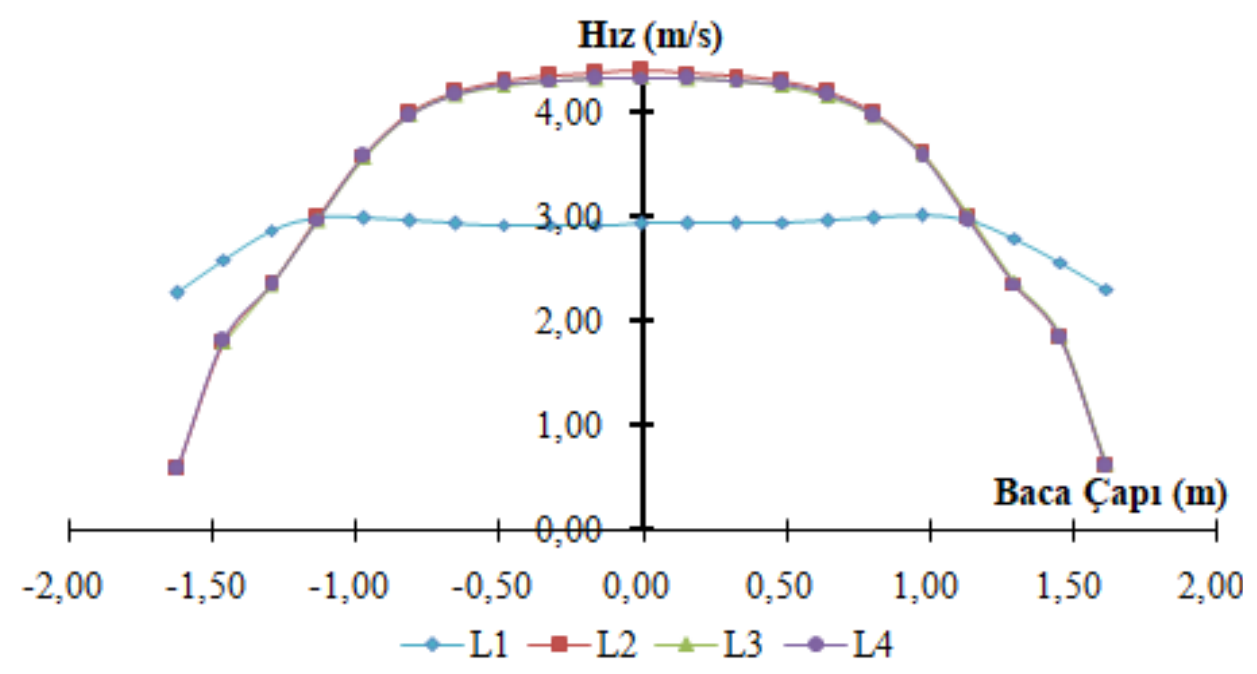

Şekil 5. L1, L2, L3 ve L4 düzlemlerinin merkezlerinden geçen x-simetri ekseni çizgisi boyunca hız dă̆ı̆lımı

Şekil 5'de L1, L2, L3 ve L4 düzlemlerinin merkezlerinden geçen $\mathrm{x}$-simetri ekseni çizgisi boyunca kepsilon türbülans modeli çözümünden elde edilen hız dağılımı gösterilmektedir. L1 düzleminin hız profilinin diğer düzlemlerin hız profillerinden daha düşük olduğu gözlemlenmiştir. L2, L3 ve L4 düzlemlerinin hız profilleri incelendiğinde, x-simetri ekseni boyunca yaklaşık olarak aynı eğilimde oldukları ve bacanın duvarlarına doğru L1 düzleminden daha hızlı azaldığı görülmektedir.

Şekil 6'da baca merkezinin y ekseni doğrultusu boyunca bacanın girişinden çıkışına kadar z-ekseni doğrultusunda çizilen çizgiler üzerindeki hız dağılımlarını göstermektedir.

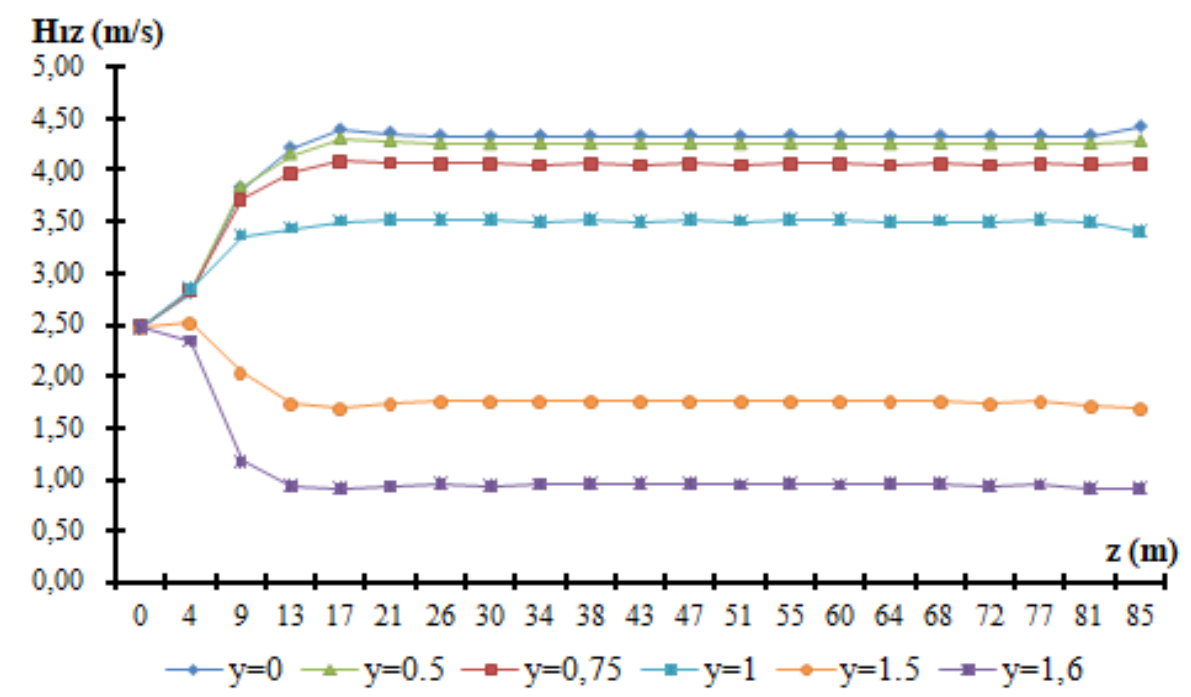

Şekil 6. Bacanın girişinden çıkışına kadar z-ekseni doğrultusunda çizilen çizgiler üzerindeki hız dă̆ılımları

Bacanın y-ekseni boyunca belirlenen noktalardan z- ekseni doğrultusunda çizilen çizgiler üzerindeki hız profilleri incelendiğinde; bacanın merkezine yakın çizgilerde $0-15 \mathrm{~m}$ arasında hızın arttı̆̆ 1 ancak baca duvarlarına yakın çizgilerde ise $0-15 \mathrm{~m}$ arasında azalma eğiliminde olduğu görülmektedir. Hız profillerinin $15 \mathrm{~m}$ 'den sonra belirlenen tüm çizgilerde yaklaşı olarak sabit bir eğilimde olduğu görülmüştür. 


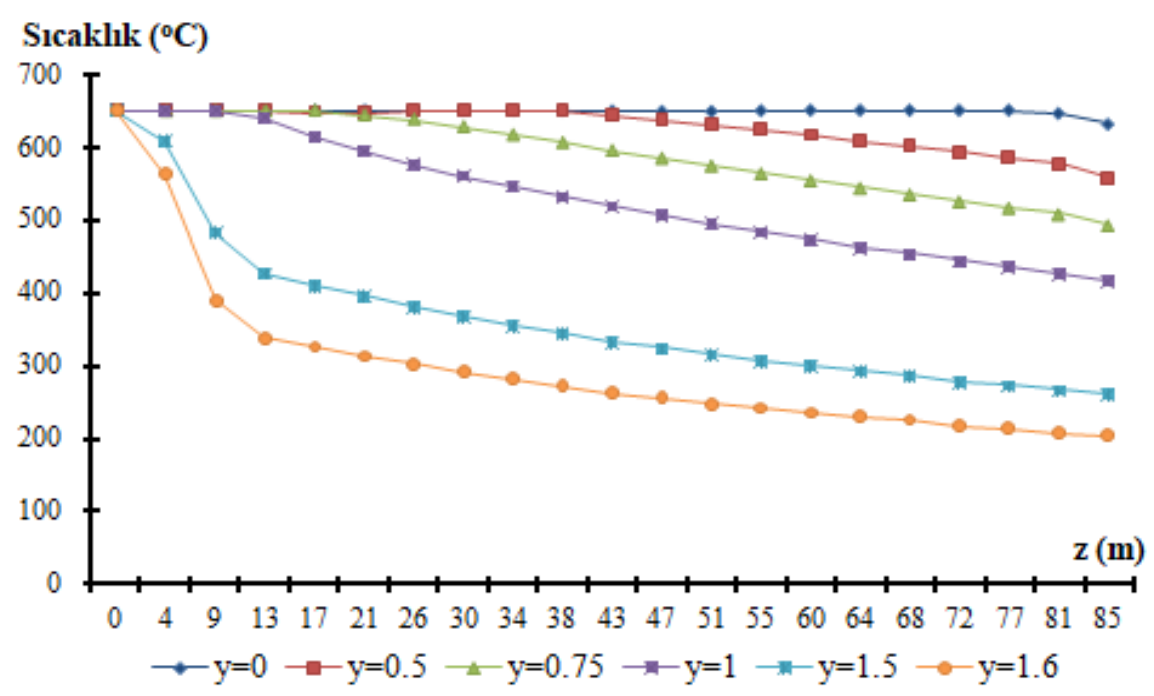

Şekil 7. Bacanın girişinden çıkışına kadar z-ekseni doğrultusunda çizilen çizgiler üzerindeki sıcaklık

$$
\text { dağılımları }
$$

Şekil 7'de baca merkezinin y ekseni doğrultusu boyunca bacanın girişinden çıkışına kadar z-ekseni doğrultusunda çizilen çizgiler üzerindeki sıcaklık dağılımlarını göstermektedir. Bacanın merkezindeki y=0 noktasında z-ekseni boyunca sıcaklığın sabit kaldığı ancak baca duvarlarına yaklaştıkça sıcaklığın daha hızlı azaldığı gözlemlenmiştir. Baca duvarlarına yakın çizgilerde sıcaklıkta ani düşüşlerin meydana geldiği görülmektedir.

\section{SONUÇ (CONCLUSION)}

Bu çalışmada baca girişinden çıkışına kadar çeşitli kesitlerde meydana gelen sıcaklık ve hız alanları belirlenmiş ve k-epsilon türbülans modelinde bu alanların etkileşimleri araştırılmıştır. Elde edilen ilk belirlemelere göre, baca çıkışına doğru yaklaşıldıkça, hız profilinde artış gözlemlenmiştir. Bu duruma bacanın ilk 3-7m aralığında çap küçülmesinin neden olduğu söylenebilir. Bacanın duvarlarına yakın bölgelerde egzoz gazı hızının sıfıra yakınsadığı gözlemlenmiştir. Baca girişinden çıkışına doğru ilerledikçe, gaz karışımının sıcaklığı azalmaktadır. Baca içinde daha yüksek seviyelere çıkıldıkça, bacanın merkezi ile duvarları arasında oluşan sıcaklık farkında da bir azalma meydana gelmektedir. Bacanın çıkışında ortalama sıcaklık değeri $460^{\circ} \mathrm{C}$ olduğu görülmüş ve ekonomizersiz endüstriyel tav firınlarında 1sı kaybının büyük oranda baca gazlarından olduğu sayısal analiz sonucunda da görülmüştür. Bir zemin çalışması niteliğinde olan bu çalışmada; HAD analizi Autodesk CFD programı ile yapılan sıcak haddehane tav firını bacasının sıcaklık ve hız alanları değerlendirildiğinde doğru sonuçlar verdiği söylenebilir. Bu çalışma sonucunda elde edilen veriler çerçevesinde 1s1 geri kazanımı uygulamalarında yapılacak olan çalışmalar için Autodesk CFD programının ve k-epsilon türbülans modelinin kullanılması tavsiye edilmektedir.

\section{KAYNAKLAR (REFERENCES)}

[1] S. McAllister, J. Chen, and A. C. Fernandez-Pello, Thermodynamics of Combustion, Fundamentals of Combustion Processes. 1st Edition, Springer, USA, 18-20, 2011.

[2] U.K. Terzi, R. Baykal, Efficient and effective use of energy: A case study of Tofas, Environmental Research, Engineering and Management, 1:55, 29-33, 2011. 
[3] B. Şimşek, E.H. Şimşek, T. Altunok, Empirical and statistical modeling of heat loss from surface of a cement rotary kiln system, Journal of the Faculty of Engineering and Architecture of Gazi University 28(1):59-66, 2013.

[4] C. Xu, D. Cang, A brief overview of low $\mathrm{CO}_{2}$ emission technologies for iron and steel making, Journal of Iran and Steel Research, 17: 3, 1-7, 2010.

[5] M. A. Topbaş, Endüstri Fırınları, Cilt 1, 1991.

[6] G. Ertem, B. Çelik, S. Yeşilyurt, Endüstriyel Tav Fırınlarında Isı Denkliği Hesaplamaları ve Enerji Verimliliğinin Belirlenmesi, IV. Ege Enerji Sempozyumu, İzmir, 1-8, 21-23, 2008.

[7] Y.Q. Wang, Q.W. Dong, M.S. Liu, D. Wang, Numerical Study On Plate Fin Heat Exchangers With Plain Fins And Serrated Fins At Low Reynolds Number, Chemical Engineering And Technology, 2009. 